\title{
1. Exploring family demography in Asia through the lens of fertility preferences
}

\section{John Casterline and Stuart Gietel-Basten}

From the standpoint of global population dynamics, the domain of this volume is of indisputable importance. The large set of countries that collectively comprise "Asia" at present contain a majority of the global population $(60 \%$ in 2015$)$ and this will continue to be the case at mid-century $(54 \%$ in 2050 according to United Nations projections (United Nations Population Division 2017)). That population levels and trends are heavily determined by levels and trends in fertility is a firmly established demographic truth, indeed fertility stands as one of the three elements in the demographic balancing equation (the other two being mortality and migration).

Fertility is fundamental to population dynamics - about this there can be no dispute. Total fertility rates (TFR) are the "headline" figures so often referred to. The variation across the region, as shown in Figure 1.1, is immense (Gietel-Basten 2018). Indeed, one can argue that Asia has some of both the highest and lowest TFRs in the world. But what about fertility desires, the theme of this volume? Should fertility desires be viewed as a central driver of fertility levels and trends, or as an epiphenomenon, i.e. simply a mediating factor through which the more fundamental determinants operate? In fact, these two stances are not incompatible, indeed canonical fertility theory encompasses both. Notably, the influential Easterlin Synthesis Framework (Easterlin 1975) accords considerable determining power to fertility desires but is also explicit that desires serve to mediate the causal effects of cultural, social and economic variables (see also National Academy of Sciences, Panel on Fertility Determinants 1983). More autonomy to fertility desires is posited by Coale in his three preconditions for fertility decline (Coale 1973), and this is the case to an even greater extent in the various "ideational" explanations derived from the empirical research of Coale and his collaborators on the European fertility decline (see, e.g., Lesthaeghe 1983, Watkins 1986, Cleland and Wilson 1987). 


\begin{tabular}{|c|c|c|c|c|c|c|c|}
\hline Eastern Asia & 1950-1955 & 1960-1965 & 1970-1975 & 1980-1985 & 1990-1995 & 2000-2005 & 2010-2015 \\
\hline China & 6.0 & 6.2 & 4.8 & 2.6 & 1.9 & 1.6 & 1.6 \\
\hline China, Hong Kong SAR & 4.4 & 5.1 & 3.0 & 1.7 & 1.3 & 1.0 & 1.2 \\
\hline China, Macao SAR & 4.4 & 4.4 & 1.8 & 2.1 & 1.4 & 0.8 & 1.2 \\
\hline China, Taiwan Province of China & 6.7 & 5.3 & 3.3 & 2.2 & 1.8 & 1.3 & 1.1 \\
\hline Dem. People's Republic of Korea & 3.5 & 3.9 & 4.0 & 2.8 & 2.3 & 2.0 & 2.0 \\
\hline Japan & 3.0 & 2.0 & 2.1 & 1.8 & 1.5 & 1.3 & 1.4 \\
\hline Mongolia & 5.6 & 7.5 & 7.5 & 5.8 & 3.3 & 2.1 & 2.8 \\
\hline Republic of Korea & 5.7 & 5.6 & 4.0 & 2.2 & 1.7 & 1.2 & 1.2 \\
\hline \multicolumn{8}{|l|}{ Central Asia } \\
\hline Kazakhstan & 4.4 & 4.4 & 3.6 & 3.0 & 2.6 & 2.0 & 2.7 \\
\hline Kyrgyzstan & 4.4 & 5.6 & 5.1 & 4.2 & 3.6 & 2.5 & 3.1 \\
\hline Tajikistan & 5.4 & 6.8 & 6.8 & 5.6 & 4.9 & 3.6 & 3.5 \\
\hline Turkmenistan & 5.3 & 6.8 & 6.2 & 4.8 & 4.0 & 2.8 & 3.0 \\
\hline Uzbekistan & 5.3 & 6.5 & 6.2 & 4.8 & 4.0 & 2.5 & 2.4 \\
\hline \multicolumn{8}{|l|}{ Southern Asia } \\
\hline Afghanistan & 7.5 & 7.5 & 7.5 & 7.5 & 7.5 & 7.2 & 5.3 \\
\hline Bangladesh & 6.4 & 6.8 & 6.9 & 6.0 & 4.1 & 2.9 & 2.2 \\
\hline Bhutan & 6.7 & 6.7 & 6.7 & 6.4 & 5.1 & 3.1 & 2.2 \\
\hline India & 5.9 & 5.9 & 5.4 & 4.7 & 3.8 & 3.1 & 2.4 \\
\hline Iran (Islamic Republic of) & 6.9 & 6.9 & 6.2 & 6.5 & 4.0 & 2.0 & 1.7 \\
\hline Maldives & 6.0 & 7.1 & 7.2 & 7.3 & 5.2 & 2.6 & 2.2 \\
\hline Nepal & 6.0 & 6.0 & 5.9 & 5.6 & 5.0 & 3.6 & 2.3 \\
\hline Pakistan & 6.6 & 6.6 & 6.6 & 6.4 & 5.7 & 4.2 & 3.7 \\
\hline Sri Lanka & 5.8 & 5.2 & 4.0 & 3.2 & 2.4 & 2.3 & 2.1 \\
\hline \multicolumn{8}{|l|}{ South-Eastern Asia } \\
\hline Brunei Darussalam & 6.9 & 6.7 & 5.5 & 3.8 & 3.1 & 2.0 & 1.9 \\
\hline Cambodia & 6.9 & 6.9 & 6.2 & 6.4 & 5.1 & 3.4 & 2.7 \\
\hline Indonesia & 5.5 & 5.6 & 5.3 & 4.1 & 2.9 & 2.5 & 2.5 \\
\hline Lao PDR & 5.9 & 6.0 & 6.0 & 6.4 & 5.9 & 3.9 & 2.9 \\
\hline Malaysia & 6.3 & 6.4 & 4.7 & 4.0 & 3.4 & 2.5 & 2.1 \\
\hline Myanmar & 6.0 & 6.1 & 5.7 & 4.7 & 3.2 & 2.9 & 2.3 \\
\hline Philippines & 7.4 & 7.0 & 6.0 & 4.9 & 4.1 & 3.7 & 3.1 \\
\hline Singapore & 6.6 & 5.1 & 2.8 & 1.7 & 1.7 & 1.3 & 1.2 \\
\hline Thailand & 6.1 & 6.1 & 5.1 & 2.9 & 2.0 & 1.6 & 1.5 \\
\hline Timor-Leste & 6.4 & 6.4 & 5.5 & 5.4 & 5.7 & 7.0 & 5.9 \\
\hline Viet Nam & 5.4 & 6.4 & 6.3 & 4.6 & 3.2 & 1.9 & 2.0 \\
\hline \multicolumn{8}{|l|}{ Western Asia } \\
\hline Armenia & 4.5 & 4.5 & 3.0 & 2.5 & 2.4 & 1.7 & 1.7 \\
\hline Azerbaijan & 5.2 & 6.0 & 4.6 & 3.3 & 2.9 & 1.9 & 2.1 \\
\hline Bahrain & 7.0 & 7.2 & 6.0 & 4.6 & 3.4 & 2.7 & 2.1 \\
\hline Cyprus & 3.7 & 3.4 & 2.5 & 2.4 & 2.3 & 1.6 & 1.4 \\
\hline Georgia & 2.8 & 2.9 & 2.6 & 2.3 & 2.1 & 1.6 & 2.0 \\
\hline Iraq & 7.3 & 6.6 & 7.2 & 6.4 & 5.6 & 4.7 & 4.6 \\
\hline Israel & 4.3 & 3.8 & 3.8 & 3.1 & 2.9 & 2.9 & 3.0 \\
\hline Jordan & 7.4 & 8.0 & 7.8 & 7.0 & 5.0 & 3.9 & 3.6 \\
\hline Kuwait & 7.2 & 7.3 & 6.8 & 5.0 & 2.6 & 2.6 & 2.1 \\
\hline Lebanon & 5.7 & 5.7 & 4.7 & 3.7 & 2.8 & 2.0 & 1.7 \\
\hline Oman & 7.3 & 7.3 & 7.4 & 8.3 & 6.3 & 3.2 & 2.9 \\
\hline Qatar & 7.0 & 7.0 & 6.8 & 5.5 & 3.7 & 3.0 & 2.0 \\
\hline Saudi Arabia & 7.2 & 7.3 & 7.3 & 7.0 & 5.6 & 3.7 & 2.7 \\
\hline State of Palestine & 7.4 & 8.0 & 7.7 & 7.0 & 6.6 & 5.0 & 4.3 \\
\hline Syrian Arab Republic & 7.2 & 7.5 & 7.5 & 6.8 & 4.8 & 3.8 & 3.1 \\
\hline Turkey & $6 . \overline{7}$ & 6.2 & 5.4 & 4.1 & 2.9 & 2.4 & 2.1 \\
\hline United Arab Emirates & 7.0 & 6.9 & 6.5 & 5.3 & 3.9 & 2.4 & 1.8 \\
\hline Yemen & 7.4 & 7.6 & 7.9 & 8.8 & 8.2 & 5.9 & 4.4 \\
\hline
\end{tabular}

Note: Darkest grey shading indicates highest fertility through to white as lowest.

Source: UNPD 2017.

Figure 1.1 Total fertility rates, UN Territories of Asia, 1950-2015

By contrast, most micro-economic theory, from Becker $(1960,1991)$ to the present, neglects fertility desires: indeed for decades they received virtually no attention in empirical research by economists. This has changed during the past two decades, prompted in part by Pritchett's (1994) provocative and controversial piece, which argued that contemporary fertility declines 
outside the West have been due mainly to decline in fertility demand rather than reduction in unwanted fertility. More recent empirical research has modified Pritchett's conclusion: both Lam (2011) and Gunther and Harttgen (2016) attribute roughly one-half of fertility decline in the period since 1970 to reduction in unwanted fertility. Note that in this stream of research, fertility desires are featured not because the authors grant them causal primacy, rather for diagnostic purposes, specifically to assess the likely magnitude of the contribution to fertility decline of improvements in birth control.

This legacy of past research on fertility attitudes and fertility motivation, barely touched on here (the research literature is mammoth!), provides a backdrop for the collection of empirical pieces in this edited volume. Few of the chapters explicitly rely on the just-mentioned theory, but long-standing debates about the proper place of fertility desires in a grand theory of fertility and fertility change echo throughout this volume. If nothing else, the enormous amount of empirical research gathered together in this volume would be infeasible without dedication over the decades to the measurement of fertility desires in demographic surveys. This in turn can be credited to general agreement from the dawn of demographic surveys (Freedman et al. 1955, Freedman 1961) up to the present that our understanding of reproductive behaviour is enlarged and deepened when fertility desires are taken into account, wherever they are placed in a causal framework. Ultimately this reflects the fact that crucial reproductive behaviours - sexual activity, birth control, post-partum practices - are purposive behaviours. When human behaviour is purposive, explicit attention to actors' conscious motivation and goals can be illuminating. These country-by-country studies provide abundant illustration that this is the case.

Standing back and surveying the mountain of empirical evidence in this volume, what generalizations might we extract? What do the data reveal about how women and men view childbearing in the highly diverse set of countries that constitutes "Asia"? What might we infer about the determinants of very rapid recent fertility declines in some but hardly all Asian countries? And prospects for further decline, or perhaps fertility increase? The remainder of this introductory chapter submits a set of propositions that emerge from the assembled empirical evidence.

\section{IDEAL FERTILITY: THE PERSISTENCE OF A POSITIVE VALUATION OF CHILDBEARING}

In demographic surveys each woman is asked for her ideal number of children: "if you could start over, how many children would you want to 
have?" is the approximate wording of the survey item. As asked, this is a question about the woman's lifetime goal. To what extent the women's responses adjust for practical considerations is unclear; what women actually seek for themselves may be more or less than their ideal once they consider real-world constraints. Common and highly salient constraints are the costs of schooling, which can serve as a powerful incentive to limit childbearing short of an abstract ideal, and preferences for sex of children, which can be a motive to extend childbearing beyond an ideal number. This point is nicely illustrated in the chapter on Taiwan with survey data revealing that a substantial fraction of women at parity one whose ideal is two children nevertheless state that they do not intend to have a second child.

A contribution of this volume is the assembling in one place of survey estimates of the ideal number of children from two dozen countries that vary enormously along most every dimension (cultural legacy, social structure, economic wealth, family policy, stage of fertility decline). Given this variation, perhaps it is not surprising that the current average ideal number of children also varies tremendously. To take the extremes, in China the ideal falls below two children, whereas in the Central Asian republics, Pakistan, and Timor-Leste it remains at four children (or higher). Falling in between are many countries where the most recent estimates are in the range of 2.5-3.5 children; this includes Israel, Malaysia, Mongolia, Philippines, Sri Lanka, and Turkey.

More surprising than the inter-country variation is the fact that the average ideal number is decidedly greater than two children in many countries: Central Asian republics, India (taken as a whole), Indonesia, Israel, Malaysia, Mongolia, Myanmar, Pakistan, Papua New Guinea, Philippines, Sri Lanka, Timor-Leste, and Turkey. This is a majority of the Asian countries included in this volume, and it happens to include several of the most populous countries (India, Indonesia, Pakistan). The clear exceptions where the average ideal is no more than two children are China, Korea, Taiwan, Singapore, and possibly Bangladesh and Nepal. (In fact in the East Asian countries the data analysed for this volume suggest an average ideal number less than two - this is certainly the case in China, and perhaps in Korea, Taiwan, and Singapore as well.) Interestingly, even in Japan, where the period TFR has been below 2.0 for many decades, the most recent survey (2010) yields an ideal number of children of 2.4 (although the "planned" number of children is 2.1).

From these data, a clear inference is that an idealization of a moderatesize family - i.e. more than two children - remains firmly entrenched in most Asian societies. It is notable that this conclusion applies to countries where fertility decline began many decades ago and that have become 
highly urbanized and relatively prosperous societies, such as Malaysia, Philippines, and Turkey. To be sure, in these countries a substantial fraction of women regard two children as ideal. But an almost universal aversion to an ideal of one child coupled with a large segment of women whose ideal is three (or larger) produces an overall average ideal that is distinctly above 2.0. Pakistan is perhaps the most striking case: survey data over nearly a 40-year period starting in the mid-1970s show remarkable stability around an ideal of four children. This persistent attachment of Pakistani women to a moderately-large family size has occurred in the presence of considerable societal change according to conventional indicators of development such as gross national product (GNP) per capita and educational attainment.

\section{EMERGENCE OF THE ONE-CHILD IDEAL?}

An open question about post-transition societies is whether a sizable fraction of women will desire to have just one child (or even no children at all). Again, the distinction must be made between fertility ideals and reality-constrained fertility intentions, with the former often exceeding the latter, as discussed above. In low-fertility societies in the West, deliberate stopping at one child is relatively common (Myrskylä et al. 2013, Zeman et al. 2017), and a non-trivial fraction of women are childless at the end of the reproductive years (OECD 2016, Zeman et al. 2017). But typically, this occurrence is in contradiction to the woman's expressed ideal: as Sobotka and Beaujouan (2014) document, survey data from Europe through the 2000s show that the one-child ideal is rare (about $10 \%$ of women on average), although in a few countries it approaches 20\% (namely Czech Republic and Portugal). The comprehensive upto-date OECD compendium shows the same: in most countries a small minority of women, usually not exceeding $10 \%$, express a desire to have no children or just one child (OECD 2016). In the early 2000s, Goldstein et al. (2004) detected signs that the one-child ideal was becoming more prevalent in the lowest fertility societies of Europe; but in the event, subsequent multiple waves of survey data have not confirmed that this is the case. To this point, the one-child ideal has not gained much of a foothold in Western societies.

Reviewing the empirical evidence in this volume, one would conclude the same about Asian societies: the prevalence of a one-child ideal remains low in all Asian societies, with the possible exception of China. A onechild ideal in China is of considerable significance because of China's sheer demographic weight. But one cannot avoid wondering whether this 
expressed ideal is deeply felt or, rather, a concession in a survey interview to formal state policy (just recently rescinded). Tellingly, in survey data from other low-fertility Asian societies - South Korea, Singapore, Taiwan - a two-child ideal is the norm and a minority of women state that one child is a desirable goal. In the majority of countries examined in this volume, fewer than $10 \%$ of women state that one child is their ideal, just as in Europe (see citations above).

As in the West, a one-child ideal may prove to be rare in post-transition Asian societies, even where a substantial fraction of women/couples choose to terminate childbearing with one child in deference to practical considerations. Because fertility decline in most Asian societies is recent from a generational perspective, it is too early to assess the prospects for the one-child ideal establishing itself in the succession of post-transition generations. At present, if one considers the lowest fertility societies, as already noted available data indicate that the one-child ideal has been relatively common in China in recent decades. This question cannot be answered for Korea, Singapore and Taiwan, however, as the recent survey data analysed in the three chapters in this volume measure intended rather than ideal number of children. It should be noted that in all three of these countries more than $10 \%$ of women express an intended number of children of zero or one.

But these are heterogeneous societies. Might the societal average hide the existence of a segment of women/couples who aspire to have just one child? Answering this question requires digging deeper into the survey data and, in particular, stratifying the estimates by major socioeconomic and demographic factors. This is what Gietel-Basten and Rajbhar (2018) have done in their recent paper on "One-Child Ideation in India". Their analysis of the National Family and Health Survey 2005-2006 shows that although the overall fraction of women with one as their ideal number of children is less than $10 \%$, among women under age 30 , women residing in urban areas, women in the richest quintile of household wealth, and women with 12 or more years of schooling, the fraction is $20 \%$ or larger, indeed among the best-educated never married women the fraction exceeds $30 \%$. Note that these data are roughly one decade old, and it is reasonable to assume that if anything these fractions have increased since then. Analysis of this sort would be worth performing for other Asian countries. At issue is whether a sizable fraction of women who wish to have less than two children is an emergent feature of post-transition Asian societies. One might hypothesize that this will commonly be the case in complex/ stratified societies such as India. But this simple hypothesis appears to be refuted by the case of Turkey: the authors' detailed analysis of survey data from 2013, when the period TFR was 2.2, reveals that even in the highest 
socioeconomic strata the mean ideal number of children is 2.5 , from which it follows that the fraction holding an ideal of zero or one child is almost certainly less than $10 \%$.

One-child families as an emergent ideal? The evidence in hand does not support an expectation that this will become a universal feature of low-fertility Asian societies; instead it seems more likely that this is a facet of post-transition reproductive regimes that will vary across countries. Certainly, this is a phenomenon that merits continued monitoring.

\section{THE SOCIOECONOMIC GRADIENT}

Judging from the cross-national variation in the ideal number of children summarized above, one might conclude that the association in present-day Asia between conventional indicators of social/economic development and desired fertility is messy. Looking at the existing empirical patterns, one is tempted to posit a strong conditioning role for cultural factors - one might invoke religious legacy, kinship systems, socio-political dynamics (e.g. Israel), and so forth.

This would be a conclusion derived from a country-level perspective. An entirely different conclusion emerges when one examines differentials at the household level. Not all chapters engage in such analysis. But those that do - this includes Bangladesh, Malaysia, Myanmar, Nepal, Philippines, Sri Lanka, Turkey - find, with no important exceptions, that desired fertility is lower among: women residing in urban areas; better educated women; and women in wealthier households. Considering the irregularity at the national level, it is a bit surprising to observe how well behaved these associations are at the household level.

Differentials of this form - lower demand for children among women in higher socioeconomic strata - are hardly strange for those scholars familiar with empirical research conducted during the past four decades on fertility outside the West. A very common analytical exercise has been estimation at the household level of differentials in various reproductive outcomes, including fertility desires. While this large and energetic literature documents the existence of socioeconomic differentials - typically as well behaved as the findings presented in this volume - less effort has been made to reflect deeply and seriously on the implications of these findings for fertility theory, i.e. those conceptual frameworks that structure our thinking about the determination of human reproduction. Long-standing micro-economic theory of fertility, most notably the theory of Becker and his students (Becker 1960, 1991), is ambivalent about whether the demand for children should be positively or inversely associated with 
socioeconomic status. In sociology and anthropology, it is difficult to point to rigorous theory that yields clear expectations about socioeconomic differentials in desired fertility. A possible exception, which grounds itself in the East Asian experience, is Greenhalgh's compelling argument that aspirations for inter-generational social mobility can serve as a powerful motivation for fertility decline (Greenhalgh 1988). Some demographers who have reflected on this matter - the near universality of lower fertility desires among the higher socioeconomic strata - have even taken the stance that such differentials signify nothing fundamental and profound about fertility, but rather are merely a temporary consequence of sub-group leads and lags that characterize most fertility declines (e.g. see Cleland (2002) on differentials according to educational attainment).

Hence the jury is out on whether the relatively consistent householdlevel differentials in desired fertility documented in some chapters in this volume are revealing of anything fundamental about reproduction as purposive human behaviour. It is hardly a coincidence that realized fertility too shows essentially the same socioeconomic differentials in most Asian societies. As some of these societies strive to cope with negative consequences of persistent sub-replacement fertility, and in particular as policies and programs to stimulate higher fertility are devised, one suspects there is instruction to be gained from a better understanding of the structures and motives that produce the existing socioeconomic differentials.

\section{IDEAL AND ACTUAL FERTILITY: FROM EXCESS TO UNREALIZED FERTILITY}

Some of the contributions to this volume contain a joint portrait of historical trends in the ideal number of children and the fertility rate (usually the period TFR). When the average fertility rate exceeds the ideal, this can be labelled excess fertility at the aggregate level. The converse situation, in which the average ideal number of children exceeds the fertility rate, can be characterized as unrealized fertility at the aggregate level. We caution that these are descriptions of societal-level conditions that need not, and usually will not, apply to all women. Indeed, typically excess fertility societies contain a minority - sometimes a rather large minority - of women whose completed childbearing falls short of their ideal (e.g. see empirical findings in Casterline and Han 2017). Similarly, unrealized fertility societies can contain a minority of women who experience unwanted births, i.e. more births than their ideal (Sedge et al. 2014). (A further technical point is that the comparison of desired and actual fertility should make use of a purely attitudinal measure of desired fertility and not the "wanted TFR", because 
the latter by design cannot exceed the TFR. A comparison of the TFR and the wanted TFR will never produce an unrealized fertility society, even though clearly there are many societies in which the average ideal exceeds the TFR.)

From a close reading of the country studies in this volume, one can infer that a feature of fertility decline in Asia has been a transition from excess fertility to unrealized fertility. To be sure, most of the country studies do not present sufficient data to draw this conclusion with confidence. Among the sub-set of countries where empirical data is presented spanning fertility decline from at least a moderate level of fertility (e.g. TFR at least 3.5) through to replacement-level fertility (or lower), the observed regularity is actual fertility exceeds desired fertility in the pre-decline and early-decline stages, with a reversal by the end of observation (typically during the past decade) when actual fertility falls below desired fertility. This is the historical pattern in China, Indonesia, Korea, Mongolia, Myanmar, Sri Lanka, and Turkey. It is striking that this listing includes countries from four sub-regions of Asia (East, Southeast, South, West).

In all likelihood the same joint historical trends - from excess to unrealized fertility - typified fertility transition in Europe, although this cannot be asserted with confidence because requisite information on fertility ideals is not available for the pre- and early-decline stages. What is clear from survey data collected during the past few decades is that, like lowfertility Asian societies, European societies are currently in a condition of unrealized fertility at the aggregate level (Sobotka and Beaujouan 2014). Likewise, presumably a transition from excess to unrealized fertility was a feature of fertility declines in Latin America; however, we are unaware of a compilation of country studies equivalent to this volume that would contain the pertinent empirical evidence.

One is tempted to posit a (near-)universal: the transition from high to low fertility - an unprecedented and relatively rapid development throughout the globe during the past two centuries - among other things has been a societal transition from excess to unrealized fertility. This might indeed stand as a universal if one were to set aside Sub-Saharan Africa. In this region, while available survey data suggests that in pre-decline and earlydecline societies the fertility rate exceeded the ideal number of children, the two are not far apart, certainly not as discrepant as in Asian societies at comparable stages of fertility transition (Bongaarts and Casterline 2013, Casterline and Agyei-Mensah 2017). And it is too soon to know whether post-decline African societies will be characterized by unrealized fertility.

In short, it seems likely that in transitioning from excess to unrealized fertility, Asian societies are not departing from the historical pattern in other major regions, with the possible exception of Sub-Saharan Africa. 
But due to lack of data and truncated histories, only in Asian societies can there be some confidence that this was what occurred. The empirical studies in this volume are a valuable documentation of this central feature of fertility transition.

\section{SON PREFERENCE: RECEDING AS DETERMINANT OF FERTILITY RATE}

Chapter 2 by Dubuc provides a comprehensive and thoughtful synthesis of the evidence in this volume, and research published elsewhere, on the prevalence of the preference for sons in Asian societies and how this bears on aggregate fertility rates. Another far briefer summary in this Introduction would serve little purpose. But one conclusion from Dubuc's chapter is sufficiently important to merit emphasis by repeating here: it appears that son preference is rapidly receding as a determinant of aggregate fertility rates in Asia. This is explained by several distinct developments. One is an increasing prevalence in some Asian societies of an indifference about sex of children (or even a preference for girls). A second is the wide availability of effective means by which parents can choose the sex of their children. Together, these two developments spell the end of son preference as a powerful force toward higher fertility rates. Provided this continues, it is an empirical realization of the historical trend sketched by Guilmoto and Bongaarts (Guilmoto 2009, Bongaarts 2013).

\section{DRIVERS OF DECLINES IN THE DEMAND FOR CHILDREN}

Why the marked decline in the demand for children observed in many of the countries in this volume? Do these country studies provide any insight about the drivers? By "drivers", we are referring to the more immediate rationale - the conscious reasons - that later generations of women desire fewer children than earlier generations (i.e. fewer than their mothers or grandmothers).

There are a set of candidates as drivers, each persuasively argued in theoretical/conceptual pieces in the research literature. For the purposes of this discussion, we identify four: (i) quantity-quality tradeoff, specifically a conviction that high investment in children is crucial for their success (e.g. Becker 1960, 1991); (ii) the opportunity cost of childbearing to parents, especially women (e.g. Becker 1960, 1991); (iii) a premium on the pursuit of individual satisfactions ("self-actualization") that comes to dominate 
in modern societies (Lesthaeghe 1983); (iv) a transformative effect of improved birth control (self-efficacy effect) (Robinson and Cleland 1992, Freedman 1997, Bongaarts 2011). This is but one classification among many that could be proposed.

From this collection of country studies, what can be concluded about the drivers of declines in the demand for children? Within-country and cross-country, there is some tendency for demand for children to decline as socioeconomic development progresses, although as noted above the alignment is far from perfect. In any case, an association with socioeconomic development is not in itself helpful in adjudicating among the four hypotheses, because this association is consistent with most of the four hypotheses proposed above (certainly the first three). Rigorous testing of the relative explanatory power of the four hypotheses requires empirical materials that are, regrettably, largely unavailable. This is not to assert that nothing can be learned from existing materials. An exciting example of making resourceful use of relatively conventional survey data is the paper by Basu and Desai (2013) discussed at some length in the Gietel-Basten and Rajbhar's (2018) study on one-child ideation in India. And some of the contributions to this volume - Brunei is an outstanding example supplement survey data with findings from qualitative interviews or other types of social science information (e.g. the chapter on Israel). Throughout the volume, to their credit most of the authors have been savvy and creative in drawing inferences about the drivers of decline in desired fertility from the empirical patterns evident in the survey data, in so doing pushing the available empirical data to the limit.

But this limit is quickly reached: national demographic surveys conducted in recent decades have standardly asked for the respondent's ideal number of children and whether or not she wants any further children at the time of the survey. But there has been no probing of the rationale for the respondents' answers to these questions. Note that this survey inquiry in its standard format is unconditional. No effort is made to ascertain what expectations inform the respondents' answers (e.g. expectations about future financial status, health status, relationship status, etc.). Nor, more ambitiously, is any effort made to explore perceived costs and benefits of children, what satisfactions are anticipated from childbearing, what risks are feared, and so forth.

This is not intended as a broadside at the now well-established design of these surveys: the type of in-depth inquiry implied in the previous paragraph exceeds what is feasible in national surveys that are mandated to cover a range of topics and, first and foremost, must provide trustworthy estimates of basic population and health indicators. But to the extent the demand for children is of relevance - for example, if there is evidence that 
existing demand stymies household-level response to policies/programs intended to modify the level of fertility (anti-natalist or pro-natalist) further in-depth inquiry into childbearing attitudes/motivations might well repay the investment.

A recent illustration of the potential payoff is a follow-on to a Demographic and Health Survey (DHS) survey in Egypt in which a subsample of the DHS respondents were asked at some length about perceived costs and benefits of children along with some closely-related topics. Analysis of these data (El-Zeini 2008) revealed that having more than two children has widespread appeal among Egyptian women, and the data offered insights into the economic, social, and cultural bases for this appeal (which, as it happens, co-exist with clear-eyed recognition of the many costs of children). By probing the costs and benefits of children, the study revealed much that was not evident from the superb series of national DHS conducted in Egypt, shedding light on the stall during the past decade in the Egyptian fertility decline at TFR > 3.0. Closer to home are the Value of Children (VOC) studies carried out in several Asian countries in the 1970s (Bulatao 1975, Bulatao 1981). Two of the chapters in this volume - the chapter on the Philippines and the chapter on Singapore, both countries where VOC data were collected in the 1970s - refer back to the VOC studies and suggest that it would be worthwhile to launch a new generation of investigations in this vein.

This is a sensible proposal, and a natural take-away from this collection of country studies. These studies make an enormous contribution by documenting levels and trends in fertility desires, and as a set provide a rich and variegated portrait of attitudes toward childbearing in the sweep of countries and vast population from Japan to Turkey. With this portrait of the variation across space and time accomplished, the question "why?" - what are the underlying motivations? - is hard to suppress. We concede that a systematic multi-country effort such as the VOC project of the 1970s is probably infeasible at present. But certainly a loosely-organized, more spontaneous set of country-by-country investigations - mixtures of quantitative and qualitative information - would be in order. We can assume with some confidence that the level of fertility will remain of concern - in some settings regarded as too high, in other settings regarded as too low, but rarely at a desirable level for a sustained historical stretch. Conducting research that has the potential to inform the design of policies/programs intended to address these persistent concerns would constitute a highly worthwhile scholarly endeavour. 


\section{REFERENCES}

Basu, A. and Desai, S. (2013). Middle class dreams: India's one-child families. Paper presented at IUSSP International Population Conference, Busan, Korea, August 2013.

Becker, G. (1960). An economic analysis of fertility, pp. 209-230 in Demographic and Economic Change in Developed Countries. Princeton, NJ: Princeton University Press.

Becker, G. (1991). The demand for children, pp. 135-154 in G. Becker A Treatise on the Family, Enlarged Edition. Cambridge, Massachusetts: Harvard University Press.

Bongaarts, J. (2011). Can family planning programs reduce high desired family size in Sub-Saharan Africa? International Perspectives on Sexual and Reproductive Health 37(4): 209-216.

Bongaarts, J. (2013). The implementation of preferences for male offspring. Population and Development Review 39(2): 185-208.

Bongaarts, J. and Casterline, J. (2013). Fertility transition: Is Sub-Saharan Africa different? Population Development Review 38(Supplement): 153-168.

Bulatao, R. (1975). The Value of Children: A Cross National Study: Philippines. Honolulu, Hawaii: East-West Center.

Bulatao, R. (1981). Values and disvalues of children in successive childbearing decisions. Demography 18(1): 1-25.

Casterline, J. and Agyei-Mensah, S. (2017). Fertility desires and the course of fertility decline in Sub-Saharan Africa, pp. 84-111 in J. Casterline and J. Bongaarts (eds.) Fertility Transition in Sub-Saharan Africa. Supplement to Volume 42 of Population and Development Review.

Casterline, J. and Han, S. (2017). Unrealized fertility: Fertility desires at the end of the reproductive career. Demographic Research 36(14): 427-454.

Cleland, J. (2002). Education and future fertility trends, with special reference to mid-transitional countries, pp. 183-194 in Completing the Fertility Transition, Population Bulletin of the United Nations, Special Issue, Nos 48/49. New York: United Nations Population Division.

Cleland, J. and Wilson, C. (1987). Demand theories of fertility transition: An iconoclastic view. Population Studies 41(1): 5-30.

Coale, A. (1973). The demographic transition reconsidered, pp. 53-72 in International Population Conference, Volume I, Liege, Belgium, 1973. Liege, Belgium: IUSSP.

Easterlin, R. (1975). An economic framework for fertility analysis. Studies in Family Planning 6(3): 54-63.

El-Zeini, L. (2008). The path to replacement fertility in Egypt: Acceptance, preference, and achievement. Studies in Family Planning 39(3): 161-176.

Freedman, R. (1961). The sociology of human fertility. Current Sociology 10/11 (2): $35-121$.

Freedman, R. (1997). Do family planning programs affect fertility preferences? A literature review. Studies in Family Planning 28(1): 1-13.

Freedman, R., Goldberg, D., and Sharp, H. (1955). 'Ideals' about family size in the Detroit Metropolitan Area: 1954. Milbank Memorial Fund Quarterly 44: 327-344.

Gietel-Basten, S. (2018). Fertility decline, pp. 64-86 in Z. Zhao and A. Hayes (eds.) Routledge Handbook of Asian Demography. London: Routledge. 
Gietel-Basten, S. and Rajbhar, M. (2018). One-child ideation in India. SocArXiv, February 27. osf.io/preprints/socarxiv/mtd7x.

Goldstein, J., Lutz, W. and Testa, M.R. (2004). The emergence of sub-replacement family size ideals in Europe. Population Research and Policy Review 22(5-6): 479-496.

Greenhalgh, S. (1988). Fertility as mobility: Sinic transitions. Population and Development Review 14(4): 629-674.

Guilmoto, C. (2009). The sex ratio transition in Asia. Population and Development Review 35(3): 519-549.

Gunther, I. and Harttgen, K. (2016). Desired fertility and number of children born across time and space. Demography 53(1): 55-83.

Lam, D. (2011). How the world survived the population bomb: Lessons from 50 years of extradordinary demographic history. Demography 48(4): 1231-1262.

Lesthaeghe, R. (1983). A century of demographic and cultural change in Western Europe: An exploration of underlying dimensions. Population and Development Review 9(3): 411-435.

Myrskylä, M., Goldstein, J.R. and Cheng, Y-H.A. (2013). New cohort fertility forecasts for the developed world: Rises, falls, and reversals. Population and Development Review 39(1): 31-56.

National Academy of Sciences, Panel on Fertility Determinants (1983). A framework for the study of fertility determinants, pp. 1-26 in Determinants of Fertility in Developing Countries, Volume 1. New York: Academic Press.

OECD (2016). OECD Family Database. http://www.oecd.org/els/family/database. htm Paris: OECD, Directrate of Employment, Labour and Social Affairs, Social Policy Division.

Pritchett, L. (1994). Desired fertility and the impact of population policies. Population and Development Review 20(1): 1-55.

Robinson, W. and Cleland, J. (1992). The increase of contraceptive costs on the demand for children, pp. 106-122 in J.F. Phillips and J.A. Ross (eds.) Family Planning Programmes and Fertility. New York: Oxford University Press.

Sedge, G., Singh, S., and Hussain, R. (2014). Intended and unintended pregnancy worldwide in 2012 and recent trends. Studies in Family Planning 45(3): 301-314.

Sobotka, T. and Beaujouan, E. (2014). Two is best? The persistence of a two-child family ideal in Europe. Population and Development Review 40(3): 391-419.

United Nations Population Division (2017). World Population Prospects 2017. New York: United Nations.

Watkins, S. (1986). Conclusions, pp. 420-449 in A.J. Coale and S.C. Watkins (eds.) The Decline of Fertility in Europe. Princeton: Princeton University Press.

Zeman, K., Beaujouan, E., Brzozowska, Z., and Sobotka, T. (2017). Cohort Fertility Decline in Low Fertility Countries: Decomposition using Parity Progression Ratios. Human Fertility Database Research Report no. RR-2017-003. Rostock, Germany: Max Planck Institute for Demographic Research. 